\title{
EVOLUÇÃO DIAGENÉTICA DOS ARENITOS DA FORMAÇÃO MORRO DO CHAPÉU, GRUPO CHAPADA DIAMANTINA, NA REGIÃO DE MORRO DO CHAPÉU, BAHIA
}

\author{
Gislaine Amorés Battilani (*), Newton Sousa Gomes (**) \& Wilson José Guerra (**)
}

\begin{abstract}
The Mesoproterozoic Chapada Diamantina Group crops out in the central part of Bahia State, covering the São Francisco Craton. It is composed, from the base to the top, of the following formations: Tombador, Caboclo and Morro do Chapéu. The lower contact of the Chapada Diamantina Group is characterized by onlap with the Archean basement or by an unconformity with the Mesoproterozoic rocks of Paraguaçu Group. The upper contact with the Una Group is unconformable and characterized by a depositional hiatus. A depositional model, a rock classification and a diagenetic evolution of the Morro do Chapéu Formation are here presented based on stratigraphic profiles, outcrop description and microscopic studies in 45 thin sections. The rocks were deposited by transitional and fluvial systems. They show high mineralogical and textural maturities, and can be classified as quartz-arenites. Besides quartz and chert, which usually make up to $95 \%$ of the rock framework, feldspars, micas, heavy minerals as well as mud and carbonate intraclasts also occur. The carbonate intraclasts are frequently silicified. The presence of these intraclasts, which come from the underlying Caboclo Formation consists an important record of a depositional hiatus between both units. Nine diagenetic events could be recognized in the fluvial sandstones of the Morro do Chapéu Formation: mechanical compactation, mechanical clay infiltration, early hematite cementation, quartz overgrowths, pressure solution, secondary porosity generation, clay authigenesis, late diagenetic phases and telodiagenetic processes. The transicional sandstones, display, aditionally, four other events: a second quartz overgrowth phase, an incipient dolomitization, antraxolite and gipsite authigenesis.
\end{abstract}

\section{INTRODUÇÃO}

O exame da literatura geológica sobre a região da Chapada Diamantina, na parte central do Estado da Bahia, mostra que desde os trabalhos pioneiros de Spix \& Martius em 1817 até os dias atuais, a região tem sido palco de trabalhos científicos que abordaram com profundidade questões relacionadas a Sedimentologia, Estratigrafia, Evolução Tectônica, Geocronologia e Geologia Econômica. Entretanto, pouca atenção foi dispensada, até o presente, ao estudo da petrologia das coberturas do Cráton, que, por apresentarem pouco ou nenhum metamorfismo, podem fornecer importantes informações a respeito da evolução diagenética. Este artigo, que constitui parte de um trabalho final de Graduação em Geologia da primeira autora, sob orientação do segundo e terceiro autores (Battilani 1996), pretende contribuir, embora de forma modesta, para o preenchimento desta lacuna do conhecimento geológico que ainda persiste na Chapada Diamantina. A figura 1 apresenta o mapa geológico simplificado da área.

\section{MATERIAIS E MÉTODOS}

Os estudos realizados nos arenitos da Formação Morro do Chapéu constaram de etapas de campo com levantamento de perfis litoestratigráficos que objetivaram identificar e descrever as litofácies e as estruturas sedimentares, medir a espessura das camadas e as direções de paleocorrentes. Além disto, foram coletadas 45 amostras de rocha para estudos petrográficos. Após a coleta sistemática de amostras confeccionaram-se lâminas delgadas para estudos microscópicos. A fração argilosa foi analisada no laboratório da UFOP com o auxílio da difratometria de raio-X utilizando-se amostras orientadas, glicoladas e aquecidas. Algumas lâminas delgadas foram analisadas ao microscópio eletrônico de varredura (MEV/EDS) no Laboratório da Cia. Vale do Rio Doce, visando-se a determinação de minerais não identificados ao microscópio. Análises de microssonda eletrônica foram realizadas no Laboratório da Universidade de Brasília, com o objetivo de determinar a composição química de turmalinas detríticas e autigênicas.

\section{GEOLOGIA REGIONAL}

O Grupo Chapada Diamantina, datado do Mesoproterozóico, ocupa, estratigraficamente, o topo do Supergrupo Espinhaço na região da Chapada Diamantina. Segundo Brito Neves \& Leal (1968), este grupo é constituído, da base para o topo, pelas formações Tombador, Caboclo e Morro do Chapéu. A Formação Tombador, ocorre em onlap sobre o embasamento cristalino eoproterozóico-arqueano na região da escarpa da Serra do Tombador e, segundo Guimarães \& Pedreira (1990), com caráter transicional sobre o Grupo Paraguaçu, também do Proterozóico Médio. O contato superior do Grupo Chapada Diamantina com o Grupo Una tem caráter discordante.

Pedreira et al. (1975) estimam para o Grupo Chapada Diamantina uma espessura de $1.060 \mathrm{~m}$. Na Folha de Morro do Chapéu, o somatório das espessuras das diversas unidades implica em um total de aproximadamente, $800 \mathrm{~m}$, o que deve ser encarado com reserva, tendo em vista que a Formação Morro do Chapéu ocorre preenchendo paleovales escavados na Formação Caboclo (Rocha 1993). 

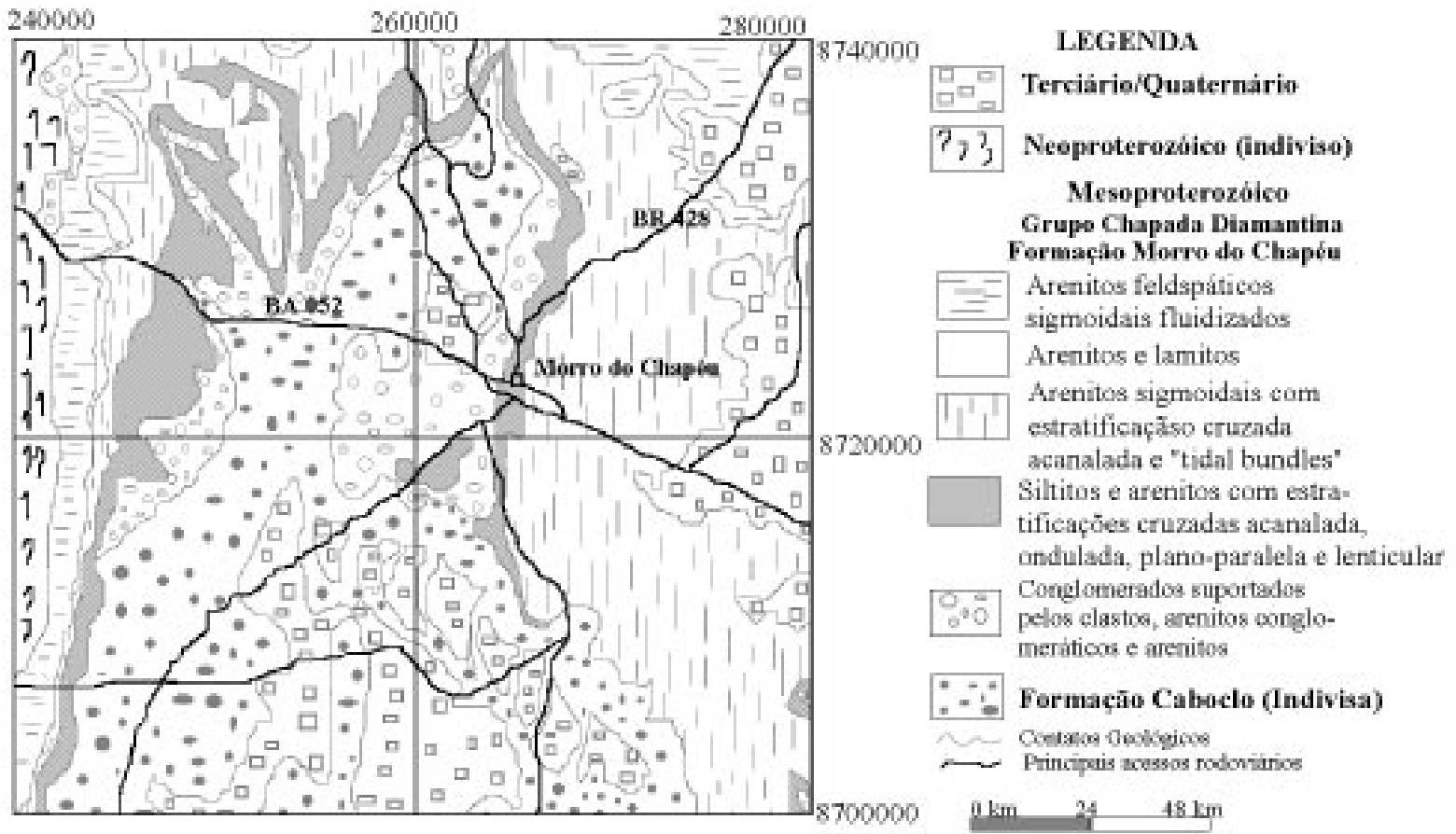

Figura 01: Mapa geológico simplificado da área estudada.(Modificado de Sampaio, et al., 1995).

Figure 01: Simplified geologic map of the studied area. (Modified from Sampaio et al. 1995)

Da base para o topo, a Formação Tombador, é constituída pelas associações de litofácies denominadas de conglomerado, arenito, arenito estratificado e arenito de granulometria grossa (Rocha 1995, in Sampaio et al. 1995).

A Formação Caboclo é a unidade que possui maior área de ocorrência na região de Morro do Chapéu, não considerando as coberturas de idade cenozóica. As litologias identificadas nesta formação são siltitos, arenitos e pelitos e, secundariamente, laminitos algais, calcarenitos e estromatólitos colunares.

Segundo Rocha, 1995 (in Sampaio et al. 1995)a Formação Morro do Chapéu é constituída por cinco associações de litofácies definidas da base para o topo como: conglomerado suportado por clastos/arenito conglomerático/arenito (sistema fluvial), siltito/arenito, arenito sigmoidal, arenito/laminito e arenito fluidizado (sistema transicional que sofreu várias flutuações do nível do mar).

\section{ASPECTOS ESTRATIGRÁFICOS E SEDIMENTOLÓGICOS}

Os estudos litoestratigráficos elaborados na área permitiram concluir que a Formação Morro do Chapéu é constituída predominantemente por arenitos de granulometria fina a média onde podem ser encontrados níveis intercalados de siltitos e lamitos e, subordinadamente, por arenito conglomerático. As estruturas primárias estão bem preservadas e indicam deposição fluvial, seguida de deposição em um ambiente costeiro raso, com pequenas oscilações do nível do mar. $\mathrm{Na}$ área estudada foram identificadas cinco associações de litofácies, denominadas, da base para o topo, de:

a) arenito/arenito conglomerático. É constituida por um arenito conglomerático suportado por grãos, culminando em um intervalo de arenitos de granulação média a grossa, caracterizando uma granodecrescência ascendente, principalmente nos festões das estratificações cruzadas acanaladas. É possível, ainda, observar uma litofácies constituída por arenitos de granulometria fina a média, os quais apresentam bimodalidade. Os corpos são lenticulares e localmente tabulares e as estruturas sedimentares observadas são estratificações cruzadas acanaladas e tabulares, laminação plano-paralela e marcas de onda no topo das camadas. A espessura aflorante é de aproximadamente 3 metros. As medidas de paleocorrentes indicam duas direções preferenciais, $\mathrm{N} 305^{\circ}$ e $\mathrm{N} 333^{\circ}$ com indíce de confiabilidade de $90 \%$ e $76 \%$. Esta associação de litofácies foi interpretada como produto de um sistema deposicional fluvial que, localmente, foi retrabalhado pelo vento.

b) siltito-argilito/arenito muito fino interlaminados. É constituída por barras de areia de granulometria muito fina intercaladas com camadas de silte e argila. As camadas possuem geometria lenticular e marcas onduladas no topo. As estruturas sedimentares mais proeminentes são estratificação cruzada de baixo ângulo, laminação plano-paralela e gretas de ressecamento. Sua espessura é de, aproximadamente, 50 metros. Suas características levaram a interpretar esta associação de litofácies como depositada em ambiente de inter-maré.

c) arenito fino a médio, pouco argiloso formando 
corpos sigmoidais. É representada por um arenito de granulação fina a média, formando camadas amalgamadas onde, localmente, ocorrem níveis milimétricos de argila entre as camadas. A forma dos corpos é sigmoidal e as estruturas mais características são estratificações cruzadas tabulares e acanaladas (apresentando padrão bidirecional), estruturas tipo espinha de peixe (herringbone) e tidal bundle, alem de laminação plano-paralela e marcas onduladas. Sua espessura varia, aproximadamente, de 18 a 30 metros. As medidas de paleocorrentes indicam duas direções preferenciais, $\mathrm{N} 330^{\circ}$ e $\mathrm{N} 10^{\circ}$, com confiabilidade de $88,8 \%$ e $66 \%$. Esta litofácies foi interpretada como depositada em ambiente dominado por marés.

d) arenitos finos/lamitos interestratificados. É constituída por barras de arenito de granulação fina intercaladas com camadas de argila. As camadas apresentam base plana e topo ondulado. Nos corpos arenosos é possível observar laminações cruzadas, estratificações lenticulares, fragmentos de lamitos, bem como, a presença de sinerese, que é comum tanto na base como no topo das camadas. Sua espessura varia, aproximadamente, de 12 a 15 metros. Interpretou-se esta associação de litofácies como representativa de um ambiente de planície de maré.

e) arenito sigmoidal fluidizado. É constituída por arenito de granulação fina a média com intercalações de níveis argilosos. Os corpos apresentam geometria sigmoidal e as estruturas sedimentares primárias são estratificações cruzadas acanaladas, fluidização, climbing ripples, drapes de argila e pequenas marcas de onda no topo das camadas. A espessura desta litofácies é da ordem de 50 metros e, ela foi interpretada como sendo representativa de uma deposição em ambiente deltáico.

\section{PETROGRAFIA}

Os estudos petrográficos indicaram que os arenitos apresentam elevado índice ZTR, altas maturidades mineralógica e textural, e inversão textural gerada pela presença de argila por infiltração mecânica. O arcabouço é sustentado por grãos que exibem predominantemente contatos do tipo flutuante e puntual, imprimindo ao empacotamento um caráter do tipo frouxo. A porosidade observada é de natureza secundária, originada principalmente pela dissolução de grãos. A composição mineralógica das rochas é constituída principalmente por cristais de quartzo monocristalinos e subordinadamente policristalinos. $\mathrm{O}$ teor de quartzo somado ao de chert ultrapassa $90 \%$ da composição mineralógica das rochas. Podem estar presentes ainda fragmentos de rochas sedimentares, raros cristais de feldspato (teor máximo de 4,71\%), cristais tabulares de mica, argilas de infiltração mecânica (ilita e caulinita), minerais opacos, óxidos de titânio, turmalina e zircão.

Com base nas observações de campo (proximidade com o embasamento cristalino e direções de paleocorrentes), inferiu-se como prováveis fontes dos sedimentos da Formação Morro do Chapéu as rochas arqueanas do embasamento e os sedimentos da própria bacia que teriam sido retrabalhados. A principal evidência deste fato é a ocorrência de fragmentos de rochas carbonáticas (oólitos silicificados) compondo o arcabouço dos arenitos (fotos 01 e 02).

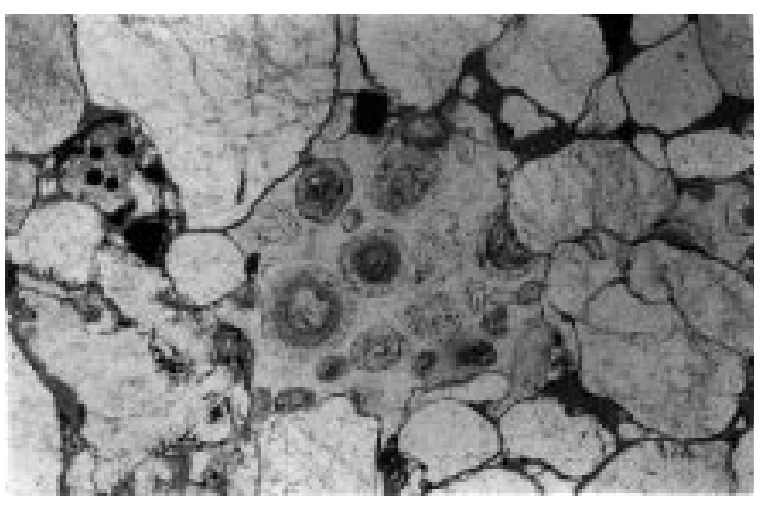

Foto 01: Fragmento de rocha carbonática silicificado. Altura da foto $2 \mathrm{~mm}$. Luz plana.

Photo 01: Carbonate rock fragment replaced by silica. Plane polarized light. Photo of 2,0 $\mathrm{mm}$ height.

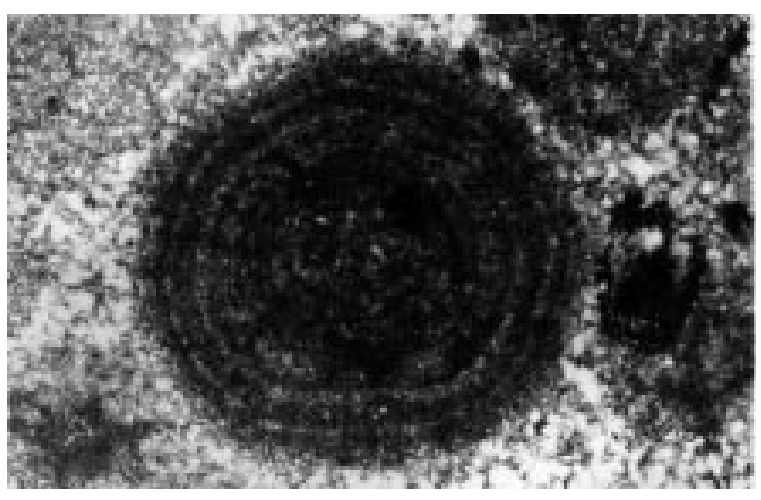

Foto 02: Detalhe da foto anterior. Oólito silicificado. Nicóis cruzados. Altura da foto 0,61 $\mathrm{mm}$.

Photo 02: Detail of photo 01. Oolite replaced by silica. Crossed nicols. Photo of 0,61 mm height.

\section{DIAGÊNESE}

\section{Introdução}

O termo diagênese foi proposto por Gümbel (1888, apud Pettijohn et al. 1987), para descrever processos químicos e físicos pós-deposicionais que modificam os sedimentos, transformando-os em rochas sedimentares. Estes processos tem início logo após a deposição dos sedimentos e se finalizam aos primeiros sinais de metamorfismo, sendo controlados pela pressão, temperatura, mineralogia primária, fluídos percolantes, ambiente deposicional e história de soterramento da bacia.

O estudo das seções delgadas dos arenitos da 
Formação Morro do Chapéu, evidenciou uma composição mineralógica pouco distinta para os ambientes fluvial e transicional, entretanto, deixou claro que a evolução diagenética destes arenitos foi bastante influenciada pelo meio deposicional e pela paleobatimetria. Durante a eodiagênese, os litotipos de ambiente transicional foram caracterizados pela cimentação precoce por hematita, enquanto nos litotipos fluviais se processou a infiltração mecânica de argilas.

\section{Evolução Diagenética}

COMPACTAÇÃO MECÂNICA - A compactação mecânica é responsável pela redução do espaço poroso e da espessura dos sedimentos devido a processos de rotação, fraturamento e deformação plástica de grãos, sendo sua intensidade controlada, principalmente, pelo volume de grãos dúcteis presentes no arcabouço da rocha (Rittenhouse 1971). Este processo diagenético foi pouco intenso nos arenitos estudados, devido a alta maturidade mineralógica e a cimentação precoce por quartzo, sendo observado, entretanto, nos poucos fragmentos argilosos (intraclastos) (foto 03) e nos raros cristais de mica que se mostram intensamente deformados.

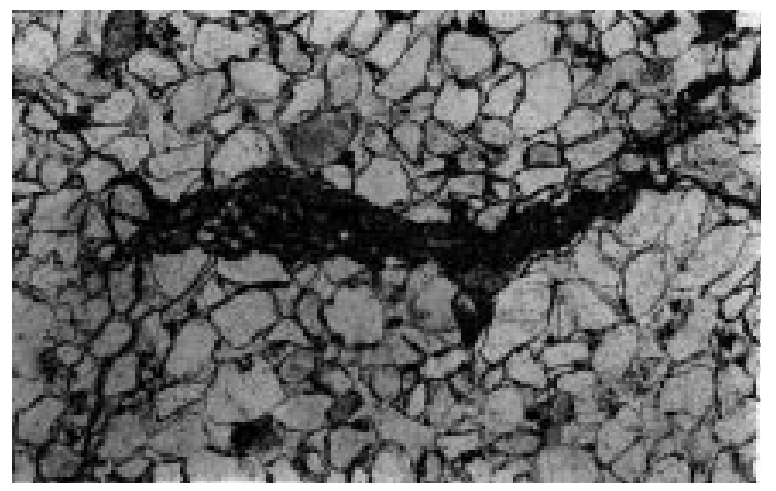

Foto 03: Intraclasto argiloso, esmagado por compactação mecânica. Luz plana. Altura da foto $2 \mathrm{~mm}$.

Photo 03: Ductile pelite intraclass deformed by mechanical compaction. Plane polarized light. Photo of 2,0 mm height.

INFILTRAÇÃO MECÂNICA DE ARGILA - Este processo tem sido descrito por diversos autores, tais como Wilson \& Pittman (1977), De Ros \& Cesero (1986), Moraes \& De Ros (1988, 1990), Matlack et al. (1989) entre outros.

De Ros \& Cesero (1986) descrevem diferentes processos ou conjunto de processos capazes de colocar uma fração argilosa nos espaços intersticiais do arcabouço de rochas clásticas, tais como: deposição simultânea, fluidização, bioturbação, compactação e infiltração.

Moraes \& De Ros (1988, 1990), ao estudarem a influência das argilas de infiltração mecânica em reservatórios fluviais da Formação Sergi, na Bacia do Recôncavo observaram o fato de que, embora o processo de infiltração mecânica seja mais eficaz em sedimentos aluviais grosseiros de clima árido, ele também ocorre em outros ambientes em escala e eficiência mais limitadas.

Matlack et al. (1989) concluem que os minerais argilosos raramente constituem mais do que poucos por cento do volume dos arenitos, entretanto sua presença tem uma profunda influência nos processos diagenéticos e na permeabilidade.

Nos arenitos da Formação Morro do Chapéu, a infiltração mecânica de argila, embora ocorra também nos arenitos do sistema transicional, mostra-se muito mais intensa nos arenitos do sistema fluvial, onde pode ser observada na forma de finas películas recobrindo grãos de quartzo.

CIMENTAÇÃO POR HEMATITA - Nas amostras estudadas, este processo diagenético é frequente, principalmente nos arenitos do sistema transicional (foto 04), nos quais se observa, em escala localizada, uma segunda geração de cimentação por hematita, a qual ocorre após a primeira fase de cimentação por quartzo. Geralmente este cimento se forma em um estágio inicial de soterramento, sob condições oxidantes. Walker $(1967,1974)$, interpreta como fonte do Fe para a cimentação por hematita a dissolução de minerais ricos neste elemento, como por exemplo biotitas e anfibólios.

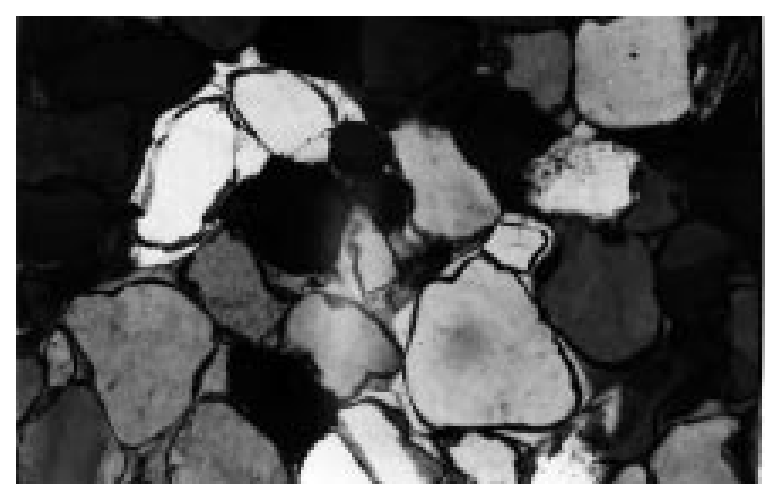

Foto 04: Cimentação precoce por hematita (película escura contornando cristais de quartzo) e intensa cimentação por quartzo (overgrowths). Nicóis cruzados. Altura da foto $1,23 \mathrm{~mm}$.

Photo 04: Early hematite cementation (dark coating surrounding quartz crystals) and intense quartz cementation (overgrowths). Crossed nicols. Photo of 1,23 $\mathrm{mm}$ height.

CIMENTAÇÃO POR QUARTZO - Este processo constitui a fase diagenética volumetricamente mais importante sendo responsável pela grande redução da porosidade primária, dos quartzo arenitos da Formação Morro do Chapéu (foto 04). A cimentação ocorre em forma de overgrowths, gerados provavelmente, no início da mesodiagênese, que apresentam formas prismáticas e continuidade ótica com os grãos detríticos. Esporadicamente, observa-se uma segunda geração de overgrowths de quartzo, interpretados como pertencentes a uma fase mesodiagenética tardia.

A fonte de sílica necessária para desenvolver a 
cimentação por quartzo, tem sido amplamente discutida, podendo ser derivada de diferentes processos, tais como: dissolução de silicatos instáveis, palagonitização, processos biogênicos, dissolução de quartzo por pressure solution e reações minerais envolvendo a liberação de sílica (Bjorlykke \& Egeberg 1993). Fontes externas, como por exemplo a percolação de águas saturadas em sílica, têm sido apontadas como um mecanismo eficiente por alguns autores, Blatt (1979).

Como fontes da sílica, responsáveis pela intensa cimentação de quartzo, que se observa nos arenitos da Formação Morro do Chapéu, pode-se admitir a liberação de sílica por pressure solution nas unidades subjacentes além da dissolução de silicatos instáveis do arcabouço da própria rocha. Gomes et al. (1996) mostram que os arenitos da Formação Tombador, unidade basal do Grupo Chapada Diamantina, apresentam intensa dissolução por pressão.

ANTRAXOLITO - O termo antraxolito foi proposto por Chapman em 1888 (apud Dunn \& Fisher 1954) para designar material semelhante ao antracito que ocorria disseminado em rochas sedimentares. Suas propriedades físicas são: dureza variando de 2 a 4 , brilho submetálico para graxo, fratura conchoidal e densidade entre 1,321,51. Trata-se de uma substância amorfa, infusível, que possui estrutura botrioidal e é insolúvel em tetracloreto de carbono, benzeno, acetona, tolueno, dissulfeto de carbono, sendo decomposta na presença de ácido sulfúrico concentrado.

O antraxolito foi descrito por Vanuxen (1842, apud Dunn \& Fisher 1954), que observou a presença de substância carbonosa negra em rochas do Paleozóico Inferior de Mohawk Valley, a qual ele denominou de antracito. Inostranzeff (1880, apud Dunn \& Fisher 1954), descreveu material similar na região entre o Mar Branco e o Lago Onega na URSS e denominou de schumgite, homenagem a península de Shunga. Pike (1949, apud Dunn \& Fisher 1954) estudando cristais de quartzo da área de Little Falls, descreveu a presença de material carbonoso ocorrendo em forma de inclusões no mineral e disseminado nas rochas sedimentares, sem entretanto tecer conjecturas a respeito de sua gênese.

Dunn \& Fisher (1954), ao estudarem a mesma área, descrevem a presença do antraxolito, ocorrendo em

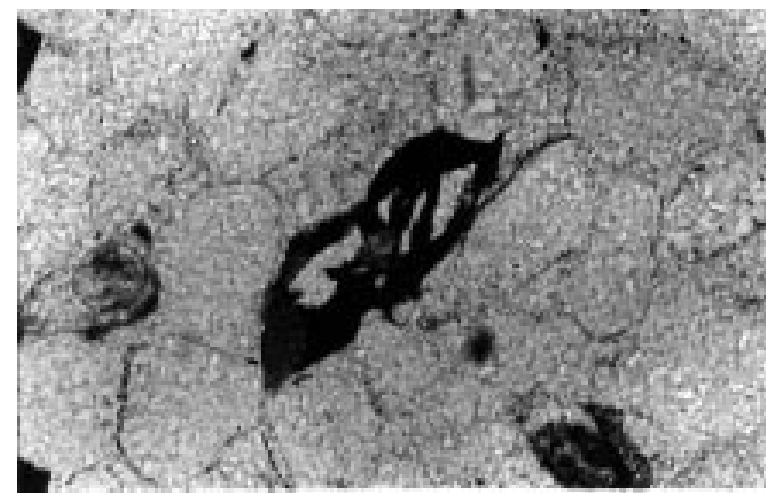

Foto 05: Antraxolito substituindo cristal de quartzo. Luz plana. Altura da foto $0,61 \mathrm{~mm}$.

Photo 05: Antraxolite replacing quartz crystal. Plane polarized light. Photo of 0,61 $\mathrm{mm}$ height. pequenas quantidades, distribuídas aleatoriamente em uma sequência carbonática do Cambriano Superior e Ordoviciano Inferior. Segundo estes autores, o antraxolito preenche o espaço poroso e dissemina-se em cristais de quartzo e calcita. Os autores concluem que o antraxolito se formou, provavelmente, a partir de matéria orgânica vegetal sob condições de pressão máxima de $300 \mathrm{~atm}$ e temperatura em torno de $50-60^{\circ} \mathrm{C}$.

Runnells (1965), estudando os depósitos de dolomita de Ruby Creek, datados do Devoniano, em Cosmos Hills, Alasca, descreve a presença do antraxolito substituindo cristais de dolomita recristalizada e também na forma de grãos sub-angulares dispersos em pequenos veios irregulares ou longitudinais e ainda como concentrado de pequenas partículas ao longo de superfícies de estilolitização.

Runnells (1965), classificou o antraxolito como sendo de origem epigenética, derivado de matéria orgânica depositada contemporaneamente com os sedimentos carbonáticos. Segundo este autor, a maior evidência de que o antraxolito foi derivado de matéria orgânica primitiva é a presença de matéria orgânica presente em cristais de dolomita não recristalizados e a ausência deste material na dolomita recristalizada.

Mancuso et al. (1989) com base em resultados de reflectância de vitrinita, de análises químicas e de isótopos estáveis, em amostras de antraxolito, oriundas de rochas do Proterozóico Inferior, de diversos afloramentos da região dos Grandes Lagos, nos Estados Unidos e Canadá, concluem que os processos de geração e migração de petróleo, semelhantes aos descritos no Fanerozóico, já teriam ocorrido desde o Pré-Cambriano.

Dentre os trabalhos sobre a ocorrência do antraxolito em rochas do Pré-Cambriano, podem ser citados ainda os de Migachev et al. (1971), Haytsu et al. (1983), Premovic et al. (1988) e Morey (1994).

Nas amostras da Formação Morro do Chapéu, foi detectada a ocorrência de um material opaco, de provável origem autigênica, que ocorre apresentando forma romboédrica (semelhante à dolomita), substituindo minerais como quartzo e feldspato e preenchendo poros (fotos 05 e 06). Análises ao microscópio eletrônico de varredura (MEV/EDS), indicaram ser esta substância constituída essencialmente por material carbonoso.

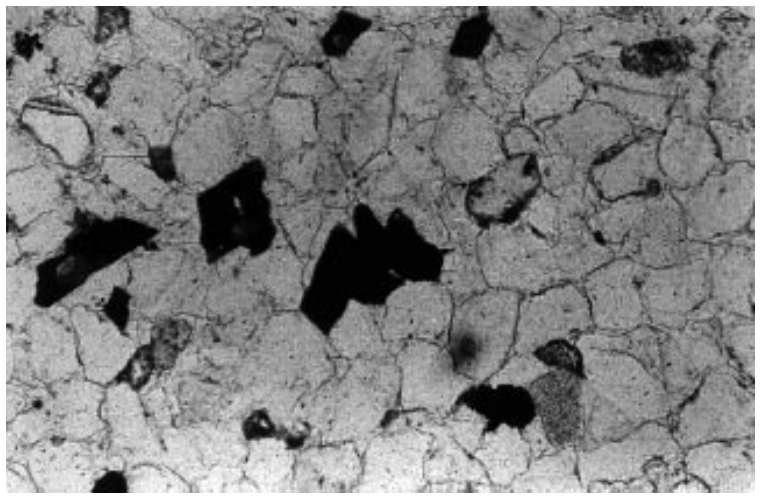

Foto 06: Detalhe para a forma romboédrica, apresentada pelo antraxolito. Luz plana. Altura da foto 1,23mm.

Photo 06: Detail of rhomboedric form showed by antraxolite. Plane polarized light.

Photo of 1,23 mm height. 
As pesquisas bibliográficas, somadas à forma de ocorrência do mineral, levam a inferir que o mineral opaco de origem autigênica presente nas amostras seja o antraxolito.

Apesar de não ter sido constatada a presença de dolomita nas amostras estudadas, o fato do antraxolito não possuir forma definida, ou seja, ser amorfo, aliado à forma romboédrica sob a qual ele ocorre, levam a inferência que o mesmo esteja substituindo cristais de dolomita, previamente formados.

PRESSURE SOLUTION - O aumento da profundidade de soterramento das rochas sedimentares provoca a elevação da pressão gerando um incremento na solubilidade de grãos de quartzo e consequentemente a dissolução por pressão ou pressure solution. Houseknecht, (1984, 1987) conclui que o tamanho dos grãos e a temperatura exercem grande influência neste processo.

Alguns autores têm atentado para o fato de que além da pressão, outros fatores também contribuem para o desenvolvimento da pressure solution. Engelhardt (1960) observou que defeitos na estrutura interna dos cristais aceleram o processo de dissolução. Heald (1955), constatou que a granulometria é também um fator controlador da dissolução, sendo que cristais de quartzo microcristalinos se dissolvem mais rapidamente que os de quartzo macrocristalinos, quando submetidos a esforços de pressão dirigida.

A pressure solution é um processo bem documentado em quartzo-arenitos, podendo a sílica gerada pela dissolução migrar para os poros, e se precipitar sob a forma de overgrowths de quartzo (Hayes 1979).

Muitos autores têm enfatizado a importância da presença de argila para o desenvolvimento dos contatos originados por pressure solution. Segundo Heald (1956), teores limitados de argila são, geralmente, suficientes para promover ou acelerar a pressure solution.

Nos arenitos da Formação Morro do Chapéu a presença de material argiloso exerceu grande influência no desenvolvimento do processo de pressure solution pois, ao serem dissolvidas as argilas liberam elementos químicos como o potássio, que alteram sensivelmente o

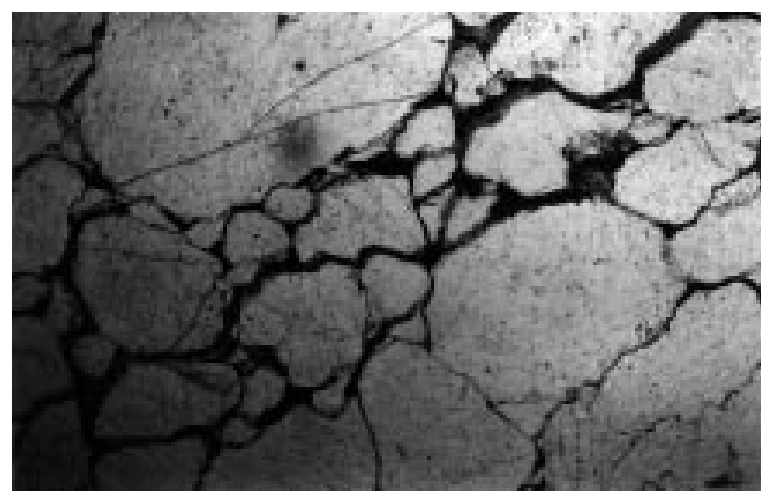

Foto 07: Estilolitos gerados por pressure solution. Luz plana. Altura da foto $1,23 \mathrm{~mm}$.

Photo 07: Stylolites generated by pressure solution. Plane polarized light. Photo of 1,23 $\mathrm{mm}$ height.
pH da água de formação, facilitando assim o desenvolvimento da pressure solution. Embora este processo tenha sido identificado nas diferentes associações de litofácies ele é mais intenso nos arenitos fluviais, nos quais foi verificada uma maior presença de finas películas de argila em torno dos grãos de quartzo (foto 07).

POROSIDADE SECUNDÁRIA - O estudo de porosidade secundária recebeu atenção maior a partir de 1975, pois, até então, a maioria dos autores consideravam que somente uma pequena porção da porosidade poderia ser de origem secundária. Proshlyakov (1960, apud Schimidt \& McDonald 1979) foi o primeiro pesquisador a interpretar como secundária quantidades significativas de porosidade, que seriam formadas em subsuperfície sob a ação do quimismo de águas de formação.

Ultimamente, inúmeros trabalhos têm enfatizado o caráter secundário da porosidade dos arenitos, apresentando bases fundamentais para a sua interpretação, entre os quais, podem ser citados os de Schimidt (1976), Stanton \& McBride (1976), Schimidt \& McDonald (1979), Bjorlykke (1984), entre outros.

Nas amostras estudadas, foi possível observar a presença de porosidade secundária decorrente de dissolução parcial de grãos, dissolução total de grãos (poros móldicos), e porosidade relacionada a fraturas.

AUTIGÊNESE DE ARGILOMINERAIS - Wilson e Pittman (1977), elaboraram vários critérios para o reconhecimento de argilominerais autigênicos e discorreram sobre a frequência com que eles ocorrem nos arenitos. Esses autores indicam como morfologias básicas, reconhecidamente autigênicas, as de lamelas dispostas perpendicularmente à superfície dos grãos e o preenchimento de poros por partículas ou agregados disseminados aleatoriamente. Eles ainda citam como argilominerais autigênicos mais comuns, a caulinita, a esmectita, a ilita, a clorita e interestratificados de ilitaesmectita.

Nos arenitos da Formação Morro do Chapéu foi observada, ainda que em quantidades muito pequenas, a presença de argilominerais apresentando, em lâminas delgadas, feições características de mineral autigênico (foto 08). Os exames de difratometria de raio-X,

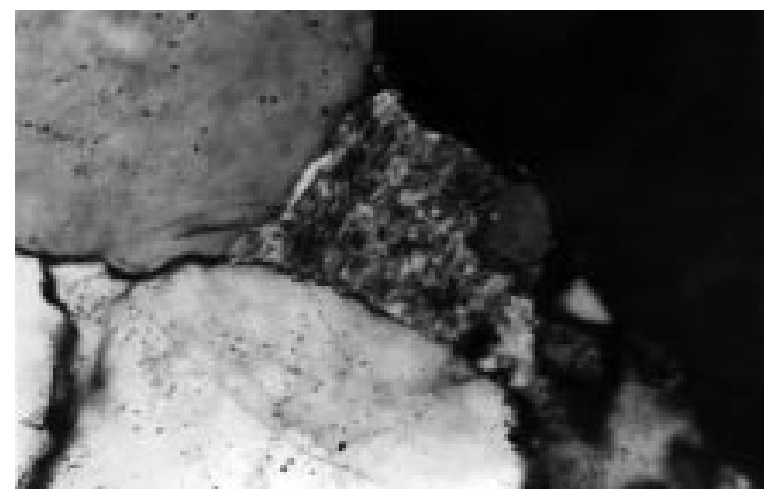

Foto 08: Argilominerais Autigênicos. Observar que os minerais de argila estão preenchendo espaço poroso entre os cristais de quartzo. Nicóis cruzados. Altura da foto $0,3 \mathrm{~mm}$.

Photo 08: Authigenic clay minerals. Note that the clay minerals are filling the pore space among the quartz. crystals. Crossed nicols. Photo of 0,3 mm height. 
indicaram a presença de ilita e caulinita, e subordinadamente pequenas quantidades de ilita/esmectita interestratificadas.

Pelo fato dos argilominerais autigênicos ocorrerem depois da formação de overgrowths de quartzo, este evento foi interpretado como tendo ocorrido no final da mesodiagênese.

AUTIGÊNESE DE GIPSITA - Nas amostras da Formação Morro do Chapéu, este mineral ocorre associado à argila autigênica, sob a forma de uma fase incolor, de baixa birrefringência, relevo baixo e habitus prismático, cuja identificação, em função do diminuto tamanho dos cristais, não foi possível através da microscopia convencional. Análises de difratometria de raio-X, entretanto, confirmaram a sua presença.

FASES DIAGENÉTICAS TARDIAS - Morad \& Aldahan (1982, 1987), De Ros (1985), Pettijhon et al. (1987), Guerra et al. (1996), entre outros, têm documentado a ocorrência de fases diagenéticas tardias em rochas de diferentes ambientes deposicionais ao longo de todo o tempo geológico.

Nos arenitos da Formação Morro do Chapéu foram identificadas como fases diagenéticas tardias a cimentação por óxidos de titânio, pirita e turmalina.

ÓXIDOS DE TITÂNIO AUTIGÊNICOS - Esses minerais estão associados a diferentes depósitos sedimentares. Suas texturas e habitus cristalinos são pouco documentados e a identificação dos polimorfos (anatásio, brookita e rutilo), ao microscópio de luz polarizada, é difícil, pois possuem características óticas muito similares (Morad \& Aldahan 1982). A sua formação é atribuída à percolação de soluções ricas em íons de Ti. Nas amostras analisadas, ocorrem pequenos cristais de óxidos de titânio autigênicos, apresentando formas idiomórficas entre os overgrowths de quartzo e preenchendo espaços porosos (foto 09).

PIRITA AUTIGÊNICA é um constituinte comum em rochas sedimentares e ocorre geralmente associada à matéria orgânica. Sua formação é o resultado da

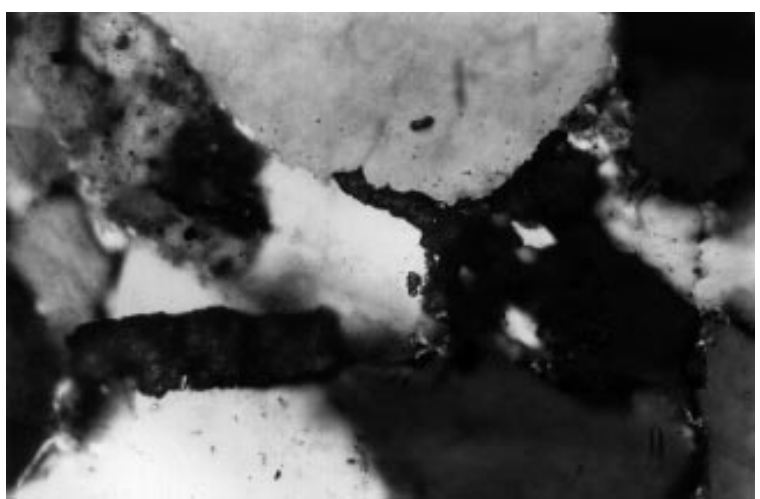

Foto 09: Óxidos de titânio autigênicos. Observar que os cristais crescem penetrando nas reentrâncias dos cristais de quartzo. Nicóis cruzados. Altura da foto $0,3 \mathrm{~mm}$.

Photo 09: Authigenic Ti-oxides. Note that the crystals grow filling cavities in quartz grains. Plane polarized light. Photo of 0,3 $\mathrm{mm}$ height. reação de $\mathrm{H}_{2} \mathrm{~S}$ com o elemento ferro, dissolvido na água de formação (Berner 1970 1984). Segundo este autor, em sedimentos marinhos depositados em águas profundas oxigenadas, a formação de pirita é limitada, principalmente pela quantidade de matéria orgânica soterrada nos sedimentos, enquanto em sedimentos marinhos depositados sob condições euxínicas, a abundância de matéria orgânica e de sulfeto de hidrogênio dá origem a altas concentrações de pirita, a qual é limitada somente pela reatividade de minerais portadores de ferro presentes no local de deposição.

A cimentação por pirita autigênica nos arenitos estudados, ocorre de forma incipiente, normalmente preenchendo espaços porosos de origem secundária. Os cristais apresentam habitus prismáticos e idiomórficos, o que permite inferir sua origem diagenética tardia.

TURMALINA AUTIGÊNICA - A sua ocorrência é bem documentada, mas pouco estudada. Estudo recente de Gomes et al. (1996), cita a ocorrência de turmalina autigênica nos arenitos da Formação Tombador. Segundo Pettijohn (1987), overgrowths de turmalina autigênica são comuns em arenitos antigos e não ocorrem em arenitos recentes. Isto é atribuído a grande lentidão para precipitar turmalina a baixas temperaturas, podendo demorar de $10^{7}-10^{8}$ anos. Este cimento, apesar de apresentar pequenas diferenças composicionais em relação ao grão detrítico ocorre em continuidade ótica com o mesmo (Pettijohn 1987).

Nos arenitos da Formação Morro do Chapéu, o cimento de turmalina ocorre com certa frequência, geralmente apresentando cores fortes (foto 10), contrastando com descrições anteriores que citam este cimento como incolor. Análises de microssonda dos overgrowths de turmalina revelaram teores mais elevados de $\mathrm{Fe}$ e mais baixos de $\mathrm{Mg}$ que os dos grãos detríticos.

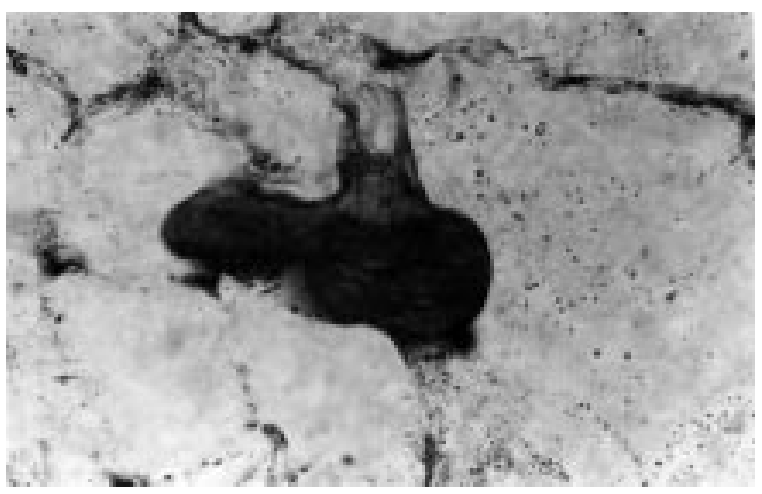

Foto 10: Turmalina autigênica. Observar que o

"overgrowth" de turmalina apresenta cor mais clara que o grão detrítico e está preenchendo espaços vazios entre os cristais de quartzo. Luz plana. Altura da foto $0,3 \mathrm{~mm}$.

Photo 10: Authigenic tourmaline. Note that overgrowths displays clearer color them the detrital grain and fills the pore space of the quartz crystals.

Plane polarized light. Photo of $0,3 \mathrm{~mm}$ height. 
FASES TELODIAGENÉTICAS - Os efeitos da telodiagênese observados nas amostras da Formação Morro do Chapéu, são pouco expressivos, podendo ser citadas a oxidação de minerais opacos e uma leve caulinização de feldspato.

\section{DISCUSSÃO DOS RESULTADOS}

O estudo petrológico dos arenitos da Formação Morro do Chapéu mostrou que, embora as rochas depositadas pelos sistemas fluvial e transicional possuam composição mineralógica semelhante, apresentam padrões de evolução diagenética bastante diferenciados. Enquanto os arenitos fluviais são caracterizados por intensa infiltração mecânica de argilas, os litotipos transicionais mostram cimentação por hematita e antraxolito. Os arenitos transicionais sofreram, provavelmente uma cimentação localizada por dolomita, que foi posteriormente substituída pelo antraxolito.

Além de uma expressiva contribuição de material retrabalhado de unidades subjacentes, formações Caboclo e Tombador, as rochas do embasamento cristalino constituíram também área fonte para os arenitos da Formação Morro do Chapéu. Essa assertiva é baseada nas direções de paleocorrentes e da proximidade das rochas do embasamento.

A ausência ou baixo teor de feldspatos em rochas do Pré-Cambriano, cuja fonte de sedimentos era o embasamento cristalino, já foi documentada e explicada por diferentes autores (Folk 1962; Mack 1984; Johnsson et al. 1988, entre outros), sendo esta ausência atribuída à instabilidade do mineral aos processos químicos e físicos, o que o torna facilmente intemperisado, além do fato de que sua dureza não suporta transporte em relevo muito acidentado e nem grandes distâncias.

\section{CONCLUSÕES}

O estudo de 45 lâminas delgadas, permitiu classificar os arenitos da Formação Morro do Chapéu em quartzo-arenitos e quartzo-arenitos conglomeráticos.

A área fonte dos sedimentos era constituída predominantemente por rochas do embasamento cristalino e subordinadamente por sedimentos retrabalhados. A alta maturidade mineralógica observada, está relacionada à dissolução de feldspatos que aumenta proporcionalmente o teor de quartzo.

A evolução diagenética das rochas da Formação Morro do Chapéu, foi controlada pelo modelo deposicional, e pela paleobatimetria e pode ser caracterizada por:

- Infiltração mecânica de argila, bastante evidenciada no sistema fluvial;

- Cimentação precoce por hematita, bem desenvolvida no ambiente transicional;

- Intensa cimentação por quartzo, principalmente no sistema transicional;

- Autigênese do antraxolito no ambiente transicional;

- Autigênese de argilominerais e formação de gipsita autigênica;

- Fases diagenéticas tardias bem desenvolvidas.

\section{AGRADECIMENTOS}

À CPRM/Salvador e em especial ao geólogo A.J.D. Rocha pelos esclarecimentos e orientações pretados durante os trabalhos de campo. Aos professores P.T. Amorim e A. pelas sugestões e discussões esclarecedoras. Aos técnicos dos laboratórios do DEGEO/UFOP que forneceram seu auxílio durante os trabalhos de laboratório e confecção final do trabalho.

Nossos sinceros agradecimentos.

\section{REFERÊNCIAS BIBLIOGRÁFICAS}

BATTILANI, G.A., 1996. Estudo do sistema deposicional da Formação Morro do Chapéu na Chapada Diamantina, Região de Morro do Chapéu, Bahia. Relatório final de Trabalho Geológico. UFOP. (inédito).

BERNER, R.A. 1970. Sedimentary pyrite formation. Am. Journ. Sci. v. 268. p. 1-23.

BERNER, R.A. 1984. Sedimentary pyrite formation: an update. Geochimica et Cosmochimica Acta. v. 48. p. 605-615.

BJORLYKKE, K. 1984. Formation of secondary porosity: how important is it? AAPG Memoir. n0 37. p. 277-286.

BJORLYKKE, K. \& EGEBERG, P.K. 1993. Quartz cementation in sedimentary basins. AAPG Bull. v. 77( 9): p. 1538-1548.

BLATT, H. 1979. Diagenetic Processes in Sandstones. In: SCHOLLE, P.A. \& SCHLUGER, P.R., eds. Aspects of Diagenesis. Soc. Econ. Paleontologists and Mineralogists, Special Publication. $n^{0}$ 26. p. 141-157.

BRITO NEVES, B.B. \& LEAL, A.S. 1968. Elementos de estratigrafia do Médio São Francisco. In: Simpósio de Geologia do Nordeste, 4. Atas...Recife: SBG.

DE ROS, L.F. 1985. Petrologia e características de reservatório da Formação Sergi, (Jurássico) no Campo de Sesmaria, Bacia do Recôncavo, Brasil. Ouro Preto. 119p. (Dissertação de Mestrado, EM/UFOP).

DE ROS, L.F. \& CESERO, P. 1986. Argilas em arenitos - Bases para a interpretação petrogenética. In: Anais de XXXIV Cong. Bras. de Geol., Goiânia, Goiás. v.4. p. 1663-1670.

DUNN, J.R. \& FISHER, D.W. 1954. Occurrence, properties and paragenesis of anthraxolite in the Mohawk Valley. Am. Journ. Sci. v. 252. p. 489-501.

ENGELHARDT,W. v. 1960. Der Porenraum der Sedimente.Springer-Verlag. Berlin. 207p.

FOLK, R.L. 1962. Bimodal supermatur sandstones: product of the desert floor. 23.Internat. Geol. Congr., Praga. v.8. p.9-32.

GOMES, N.S.; VARAJÃO, A.D.; SOUZA, P.C.; GUERRA, W.J.; AZAMBUJA FILHO, N.C. \& MENDES, G.E. 1996. Influência do modelo deposicional na evolução diagenética de arenitos proterozóicos: um exemplo da Formação Tombador, Chapada Diamantina, Bahia. Cong. Bras. Geol. 39. Salvador. v.1. p. 259262.

GUERRA, W.J.; AZAMBUJA FILHO, N.C.; GOMES, N.S. \& SOUZA, P.C. 1996. Estudo do Sistema Deposicional da Formação Tombador na Chapada Diamantina, Região de Morro do Chapéu. Relatório interno - UFOP. 77p. (inédito).

GUIMARÃES, J.T. \& PEDREIRA, A.J. (orgs.). 1990. Utinga Folha SD.24-V-A-II; Estado da Bahia. Texto Explicativo. Brasília: DNPM. 142p. Programa Levantamentos Geológicos Básicos do Brasil - PLGB. CPRM/SUREG-SA.

HAYATSU, R.; WINANS, R.E.; NEWMAN, D.S.; MANCUSO, J.J. \& SEAVOY, R.E. 1983. Correlations between the chemical and the geologic origins of anthraxolite from the Gunflint Formation, Thunder Bay, Ontario. Bull. Soc. Econ. Geologists. 78(1): 175-180. 
HAYES, J.B. 1979. Sandstone Diagenesis - The hole truth. In: SCHOLLE, P.A. \& SCHLUGER, P.R., eds. Aspects of Diagenesis. Soc. Econ. Paleontologists and Mineralogists, Special Publication. no 26. p. 127-139.

HEALD, M.T. 1955. Stylolites in sandstones. Journ. Geol. v. 63. p.101-114.

HEALD, M.T. 1956. Cementation of Simpson and St. Peter sandstones in parts of Oklahoma, Arkansas and Missouri. Journ. Geol. v. 64. p. 417-424.

HOUSEKNECHT, D.W. 1984. Influence of grain size and temperature on intergranular pressure solution, quartz cementation and porosity in a quartzose sandstone. Jour. Sed. Petrology. v. 54(2): 348-361.

HOUSEKNECHT, D.W. 1987. Assessing the relative importance of compaction processes and cementation to reduction of porosity in sandstones. AAPG Bull. 71(6): 633-642.

JOHNSSON, M.J.;STALLARD, R.F. \& MEADE, R.H. 1988. First cycle quartz arenites in the Orinoco River Basin, Venezuela and Colombia. Journ. Geology. v.96. p.263-277.

MACK, G.H. 1984. Exceptions to the relationship between plate tectonics and sandstone composition. Journ. Sed. Petrol. 54(1): $212-220$

MANCUSO,J.J.; KNELLER, W.A. \& QUICK,J.C. 1989. Precambrian vein pyrobytumen: evidence for petroleum generation and migration $2 \mathrm{Ga}$ ago. Precambrian Research. v. 44. p. 137-146.

MATLACK, K.S.; HOUSEKNETCH, D.W. \& APPLIN, K.R. 1989. Emplacement of clay into sand by infiltration. Journ. Sed. Petrlogy. v. 59. p. 77-87.

MIGACHEV. I.F.; SAAKYAN, V.M.; USPENSKIY, V.A. \& STEPANOV, A.A. 1971. Characteristics of anthracolite (anthraxolite) from Upper Proterozoic rocks. Lithology and Mineral Resources. 6(1): 101-106.

MORAD, S. 1986. SEM study of rutile, anatase and brookite in Proterozoic sandstones from Sweden. Sedimentary Geology. v. 46. p. 77 - 89.

MORAD, S. \& ALDAHAN, A.A. 1982. Authigenesis of titanium minerals in two Proterozoic sedimentary rocks from South and Central Sweden. Journ. Sed. Petrology. 52(4): 1295-1305.

MORAD, S. \& ALDAHAN, A.A. 1987. Diagenetic replacement of feldspars by titanium oxides in sandstones. Sedimentary Geology. v. 51. p. 147-153.

MORAES, M.A.S. \& DE ROS, L.F. 1988. Caracterização e influência das argilas de infiltração mecânica em reservatórios fluviais da bacia do Recôncavo, nordeste do Brasil. Bol. Geoc. Petrobrás, Rio de Janeiro. v. 2. p. 13 -26.

MORAES, M.A.S. \& DE ROS, L.F. 1990. Infiltrated clays in fluvial Jurassic sandstones of Recôncavo Basin. Northeastern Brazil. Journ. Sed. Petrol. v. 60. p. 809-819.
MOREY, G.B. 1994. Anthraxolite in the Early Proterozoic Biwabik Iron Formation, Mesabi Rage, Northern Minnesota. Report of Investigations - Minnesota Geological Survey. v. 43. p. 39-47.

PEDREIRA, A.J.C.L.; ARCANJO, J.B.; PEDROSA, C.J.;OLIVEIRA, J.E. \& SILVA,B.C.E. 1975. Projeto Bahia; Geologia da Chapada Diamantina. Relatório Final. Salvador: CPRM. v.1. Convênio DNPM/CPRM.

PETTIJOHN, F.J.; POTTER, P.E. \& SIEVER, R. 1987. Sand and Sandstone. Springer-Verlag, New York. 553p.

PREMOVIC, P.I.; KOMATINOVIC, B.V.; PUGMIRE, R.J. \& WOOLFENDEN, W.R. 1988. Solid-state C-13 NMR of middle Precambrian anthracite and related anthraxolite. Naturwissenschaften. 75(2): 98-100.

RITTENHOUSE, G. 1971. Mechanical compaction of sands containing different percentages of ductile grains: a theoretical approach. AAPG Bull. 5(1): 92-96.

ROCHA, A.J.D. (org). 1993. Morro do Chapéu Folha SC.24-Y-CV; Estado da Bahia. Texto explicativo e mapas. Brasília: CPRM. (Programa de Levantamentos Geológicos Básicos do Brasil PLGB). 170p. (No prelo).

RUNNELLS, D.D. 1965. Anthraxolite derived from indigenous organic matter in Middle Devonian dolomite, Cosmos Hills, Alaska. Journ. Sed. Petrology. 35(3): 599-603.

SAMPAIO, A.R.; SANTOS, R.A. \& ROCHA, A.J.D. (orgs.). 1995 Jacobina, folha SC.24-Y-C; Estado da Bahia. Texto explicativo. Brasília: CPRM. (PLGB-Projeto de Mapas Metalogenéticos e de Previsão de Recursos Minerais). No prelo.

SCHIMIDT,V. 1976. Secondary porosity in the Parsons Lake Sandstone (abs), Geol. Assoc. Canada Ann. Meeting Abs. v. 2. p.106.

SCHIMIDT, V. \& MCDONALD, D.A. 1979. Secondary reservoir porosity in the course of sandstone diagenesis. USA. AAPG. 125p. (Education Couse Note Series n $\mathrm{0}$ 12).

SPIX, J.V. \& MARTIUS, C.V. 1938. Reise in Brasilien. São Paulo. Editora Nacional. $342 \mathrm{p}$.

STANTON, G.D. \& MCBRIDE, E.F. 1976. Factors influencing porosity and permeability of Lower Wilcox (Eocene) sandstones, Karnes County, Texas (abs.). AAPG and Soc. Econ. Paleontologists and Mineralogists Ann. Meeting Abs. v. 1. p. 119

WALKER, T.R. 1967. Formation of red beds in modern and ancient deserts. Geol. Soc. Am. Bull. v.78. p. 353-368.

WALKER, T.R. 1974. Formation of red beds in moist tropical climates: A hipothesis. Geol. Soc. Am. Bull. 85(4): 633-638.

WILSON, M.D. \& PITTMAN, E.D. 1977. Authigenic clays in sandstones: recognition and influence on reservoir properties and paleoenvironmental analysis. Journ. Sed. Petrol. 47(1): 0331. 